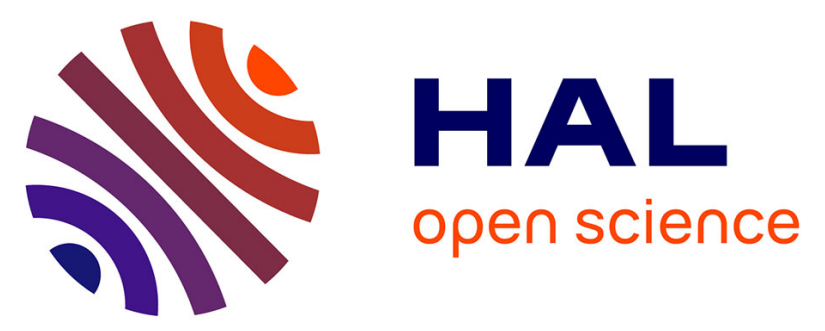

\title{
Chromosome localization of the 31 type I Texas bovine markers in sheep and goat chromosomes by comparative FISH-mapping and R-banding
}

G.P. Di Meo, A. Perucatti, Mathieu M. Gautier, Hélène Hayes, D. Incarnato, Andre A. Eggen, L. Ianuzzi

\section{To cite this version:}

G.P. Di Meo, A. Perucatti, Mathieu M. Gautier, Hélène Hayes, D. Incarnato, et al.. Chromosome localization of the 31 type I Texas bovine markers in sheep and goat chromosomes by comparative FISH-mapping and R-banding. Animal Genetics, 2003, 34, pp.294-296. hal-02676824

\section{HAL Id: hal-02676824 \\ https://hal.inrae.fr/hal-02676824}

Submitted on 31 May 2020

HAL is a multi-disciplinary open access archive for the deposit and dissemination of scientific research documents, whether they are published or not. The documents may come from teaching and research institutions in France or abroad, or from public or private research centers.
L'archive ouverte pluridisciplinaire HAL, est destinée au dépôt et à la diffusion de documents scientifiques de niveau recherche, publiés ou non, émanant des établissements d'enseignement et de recherche français ou étrangers, des laboratoires publics ou privés. 


\title{
Chromosome localization of the 31 type I Texas bovine markers in sheep and goat chromosomes by comparative FISH-mapping and R-banding
}

\author{
G. P. Di Meo*, A. Perucatti* , M. Gautier ${ }^{\dagger}$, H. Hayes $^{\dagger}$, D. Incarnato* ${ }^{*}$ A. Eggen ${ }^{\dagger}$ and L. lannuzzi* \\ *National Research Council (CNR), ISPAAM, Laboratory of Animal Cytogenetics and Gene Mapping, Naples, Italy. 'Laboratory of \\ Biochemical Genetics and Cytogenetics, Department of Animal Genetics, INRA, Jouy-en-Josas, France
}

\section{Summary}

\begin{abstract}
Bovine BAC clones containing the 31 genes, referred to as the Texas markers used earlier to definitively assign the 31 bovine syntenic groups (U) to cattle chromosomes, were mapped by fluorescent in situ hybridization to sheep and goat R-banded chromosomes according to ISCNDB2000. All 31 markers were localized on homoeologous chromosomes and chromosome bands of the two species in agreement with previous localizations obtained both in cattle and river buffalo, definitively confirming chromosome homoeologies between Caprinae and Bovinae. In addition, we have extended physical maps of sheep and goat as 11 genes (HSD3B1, INHBA, CSN10, IGF2R, PIGR, MAP1B, DSC1, ELN, TNFRSF6, CGN1, IGF2) and 14 genes (SOD1, HSD3B1, CSN1O, IGF2R, RB1, TG, PIGR, MAP1B, IGH@, LTF, DSC1, TNFRSF6, CGN1, IGF2) were assigned for the first time to goat and sheep chromosomes, respectively.
\end{abstract}

Keywords cytogenetics, goat, nomenclature, sheep, type I marker.

Chromosome nomenclatures in bovids have often represented a problem for cytogeneticists due to the nature of the autosomes (all acrocentric in cattle and goat, almost all acrocentric in river buffalo and sheep), as well as to different banding techniques used by various laboratories. For this reason, official molecular markers were assigned to each cattle chromosome during the Texas Conference (1996). Another important step was achieved when the same BACclones containing the 31 markers referred as 'Texas markers' were mapped, by fluorescent in situ hybridization (FISH), to both G/Q and R-banded cattle chromosomes (Hayes et al. 2000). This study was the basis for the latest international conference (ISCNDB2000 2001) where new standard Q-, G-, and R-banded karyotypes were arranged for cattle, sheep and goat using only one common chromosome band nomenclature.

In this study, all the 31 Texas markers, earlier assigned to both cattle (Hayes et al. 2000) and river buffalo (Iannuzzi et al. 2001a) were FISH-mapped to both sheep and goat chromosomes, definitively confirming the chromosome

Address for correspondence

L. Iannuzzi, CNR-ISPAAM, Laboratory of Animal Cytogenetics and Gene Mapping, Via Argine 1085, 80147 Naples, Italy.

E-mail: I.iannuzzi@iabbam.na.cnr.it

Accepted for publication 1 March 2003 homoeologies among these four bovids and further extending their cytogenetic maps.

Concavalin A stimulated blood cell cultures were treated for late incorporation of both BrdU $(20 \mu \mathrm{g} / \mathrm{ml})$ and Hoechst $33258(40 \mu \mathrm{g} / \mathrm{ml})$ to obtain R-banded preparations.

Slides kept at $-20{ }^{\circ} \mathrm{C}$ until use, were treated for FISHtechnique as previously reported (Iannuzzi et al. 2000). The following biotinylated probes were used: 31 bovine BACclones each containing one of the 31 type I Texas markers characterized previously (Hayes et al. 2000; Gautier et al. 2001). Fifteen metaphases were studied for each probe and species and chromosome identification followed the standard karyotypes (Ansari et al. 1999; ISCNDB2000 2001). The frequency of FITC-signals (cells with spots on one chromosome or on both chromosomes) varied from $30 \%$ (PGK1) to 70\% (DEFB@). These percentages were lower than those achieved in both cattle (Hayes et al. 2000) and river buffalo (Iannuzzi et al. 2001a), probably because of the bovine BAC-clones employed.

All 31 Texas markers mapped to homoeologous chromosomes and chromosome bands of the two species, as well as to homoeologous chromosomes and chromosome regions of sheep/goat and cattle, as reported in Table 1. This further supports the chromosome homoeology between these two species as well as between Caprinae and Bovinae. Indeed, goat and sheep chromosome localizations agree with those obtained in both cattle (Hayes et al. 2000) and river buffalo 
Table 1 List of mapped loci and their localization on sheep (OAR) and goat (CHI) chromosomes. Comparisons with cattle chromosome (BTA) localizations (Texas Conference 1996; Hayes et al. 2000; ISCNDB2000 2001), relative syntenic group (U) and presumed localizations on the basis of Ansari et al. (1999) sheep standard are also reported.

\begin{tabular}{|c|c|c|c|c|c|c|}
\hline $\begin{array}{l}\text { Locus } \\
\text { Symbol }\end{array}$ & Locus name & OAR & $\mathrm{CHI}$ & BTA & $U$ & $\begin{array}{l}\text { OAR, Ansari } \\
\text { et al. } 1999\end{array}$ \\
\hline SOD1 & superoxide dismutase 1 , soluble (amyotrophic lateral sclerosis 1 (adult) & $1 \mathrm{q} 12.2$ & $1 \mathrm{q} 12.2$ & $1 \mathrm{q} 12.2$ & U10 & $1 q 13$ \\
\hline VIL1 & villin 1 & $2 q 43$ & $2 q 43$ & $2 q 43$ & U17 & $2 q 43$ \\
\hline HSD3B1 & hydroxy-delta-5-steroid dehydrogenase, 3 beta- and steroid delta-isomerase 1 & $1 \mathrm{p} 21$ & $3 q 21$ & $3 q 21$ & U6 & $1 p 21$ \\
\hline INHBA & inhibin, beta $A$ (activin $A$, activin $A B$ alpha polypeptide) & $4 q 26$ & $4 q 26$ & $4 q 26$ & U13 & $4 q 27$ \\
\hline IFNG & interferon gamma type 2 & $3 q 23$ & $5 q 23$ & $5 q 23$ & U3 & $3 q 23$ \\
\hline CSN10 & casein, kappa & $6 q 32$ & $6 q 32$ & $6 q 32$ & U15 & $6 q 32$ \\
\hline RASA1 & GTPase activating protein RAS p21 & $5 q 25.2$ & $7 q 25.2$ & $7 q 25.2$ & $\mathrm{U} 22$ & $5 q 32$ \\
\hline IFN1@ & interferon omega & $2 \mathrm{p} 15$ & $8 q 15$ & $8 q 15$ & U18 & $2 p 15$ \\
\hline$I G F 2 R$ & insulin-like growth factor 2 receptor & $8 q 26$ & $9 q 26$ & $9 q 26$ & U2 & $8 q 26$ \\
\hline CYP19 & aromatase (cytochrome $\mathrm{P} 450$, subfamily XIX) & $7 q 26$ & $10 q 26$ & $10 q 26$ & U5 & $7 q 34$ \\
\hline$L G B$ & lactoglobulin, beta & $3 p 28$ & $11 q 28$ & $11 q 28$ & U16 & $3 p 27$ \\
\hline RB1 & retinoblastoma 1 (including osteosarcoma) & $10 q 13$ & $12 q 13$ & $12 q 13$ & U27 & $10 q 13$ \\
\hline IL2RA & Interleukine 2receptor alfa & $13 q 13$ & $13 q 13$ & $13 q 13$ & U11 & $13 q 13$ \\
\hline$T G$ & thyroglobulin & $9 q 13$ & $14 q 13$ & $14 q 13$ & U24 & $9 q 21$ \\
\hline FSHB & follicle stimulating hormone, beta polypeptide & $15 q 26$ & $15 q 26$ & $15 q 25-q 26$ & U19 & $15 q 32$ \\
\hline PIGR & polymeric immunoglobulin receptor & $12 q 12$ & $16 q 12$ & $16 q 12$ & U1 & $12 q 12$ \\
\hline FGG & fibrinogen, gamma polypeptide & $17 q 13$ & $17 q 13$ & $17 q 13$ & $\mathrm{U} 23$ & $17 q 13$ \\
\hline GPI & glucose phosphate isomerase & $14 q 24$ & $18 q 24$ & $18 q 24$ & U9 & $14 q 24$ \\
\hline GH1 & growth hormone 1 & $11 q 22$ & $19 q 22$ & $19 q 22$ & U21 & $11 q 32$ \\
\hline MAP1B & microtubule-associated protein $1 \mathrm{~B}$ & $16 q 13.1$ & $20 q 13.1$ & $20 q 13.1$ & U14 & $16 q 13$ \\
\hline$I G H @$ & immunoglobulin heavy locus & $18 q 24$ & $21 q 24$ & $21 q 24$ & U4 & $18 q 24$ \\
\hline LTF & lactotransferrin & $19 q 24$ & $22 q 24$ & $22 q 24$ & U12 & $19 q 24-26$ \\
\hline$B O L A-D Y A$ & major histocompatibility complex, class II,DY alpha & $20 q 13$ & $23 q 13$ & $23 q 13$ & $\mathrm{U} 20$ & $20 q 13$ \\
\hline DSC1 & desmocollin 1 & $23 q 21$ & $24 q 21$ & $24 q 21$ & $\mathrm{U} 28$ & $23 q 13$ \\
\hline ELN & elastin (supravalvular aortic stenosis, Williams-Beuren syndrome) & $24 q 22$ & $25 q 22$ & $25 q 22$ & U8 & $24 q 17$ \\
\hline TNFRSF6 & tumor necrosis factor receptor superfamily, member 6 & $22 q 13$ & $26 q 13$ & $26 q 13$ & U26 & $22 q 13$ \\
\hline$D E F B @$ & beta defensin gene cluster & $26 q 13$ & $27 q 13$ & $27 q 13$ & $\mathrm{U} 25$ & $26 q 13$ \\
\hline CGN1 & conglutinin 1 & $25 q 17$ & $28 q 17$ & $28 q 17$ & U29 & $25 q 21$ \\
\hline IGF2 & insulin-like growth factor 2 (somatomedin A) & $21 q 24$ & $29 q 24$ & $29 q 24$ & U7 & $21 q 23$ \\
\hline PGK1 & phosphoglycerate kinase 1 & $\mathrm{Xq} 26$ & $\mathrm{Xq} 28$ & $\mathrm{Xq} 25$ & $x$ & $x q 23$ \\
\hline$Z F Y$ & zinc finger protein $Y$-linked & Yp12 & Yp12 & Yp12 & Y & Yp12 \\
\hline
\end{tabular}

(Iannuzzi et al. 2001a). Special attention should be given to CHI25, CHI27, CHI28 and CHI29, homoeologous to OAR24, OAR26, OAR25 and OAR21, respectively. Indeed, these chromosomes have been often confused during standard karyotype constructions (reviewed in Iannuzzi et al. 1997). Details of their Q-, G- and R-banding patterns and chromosome differences have been reported in the ISCNDB2000 (2001). To confirm identification of these chromosomes in chromosome rearrangements or abnormalities, we suggest the use of FISH with official chromosome specific markers such as the Texas set of markers (Di Meo et al. 2000; Iannuzzi et al. 2001b, c, d). The presumed localizations of mapped loci made according to the sheep standard karyotype published by Ansari et al. (1999) are also reported in Table 1 (last column). The differences in band numbers are due essentially to a different numbering of landmarks and, in a few cases, to subdivision of bands.

The 31 type I markers assigned to sheep and goat in the present study extend the physical map of these two important species. Indeed, 11 genes (HSD3B1, INHBA, CSN10, IGF2R, PIGR, MAP1B, DSC1, ELN, TNFRSF6, CGN1, IGF2) and 14 genes (SOD1, HSD3B1, CSN10, IGF2R, RB1, TG, PIGR, MAP1B, IGH@,LTF, DSC1, TNFRSF6, CGN1, IGF2) were localized for the first time on goat and sheep chromosomes, respectively (GoatBase: http://locus.jouy.inra.fr/cgi-bin/ $\mathrm{lgbc} / \mathrm{mapping} / \mathrm{common} / \mathrm{main} . \mathrm{pl}$ ? BASE = goat; Sheep Base: http://www.thearkdb.org/, November 2002). Moreover, the position of some loci previously mapped in these species has been revised according to both present data and the latest chromosome nomenclature (ISCNDB2000 2001). Indeed, VIL1 maps to OAR $2 \mathrm{q} 43$ and CHI $2 \mathrm{q} 43$ (instead of OAR2q33 and CHI2q33), RASA1 maps to OAR5q25.2 (instead of OAR5q21.4), IFN1@ maps to CHI8q15 (instead of CHI8q22), CYP19 maps to OAR7q26 (instead of OAR7q24-31), LGB maps to OAR3p28 (instead of OAR3p27), GPI maps to OAR14q24 and CHI18q24 (instead of OAR14q23-26 and CHI18q22), ELN maps to OAR24q22 (instead of OAR24q16-19). 
In conclusion, the same BAC-clones containing the 31 type I Texas markers, previously localized in both cattle and river buffalo, were FISH-mapped to sheep and goat chromosomes definitively confirming chromosome homoeologies among sheep, goat, cattle and river buffalo and further supporting the common origin among the four species. To date, the only small difference between Bovinae (cattle and river buffalo) and Caprinae (goat and sheep) autosomes, revealed by comparative FISH-mapping data, concerns the Bovinae and Caprinae chromosomes 9 and 14 which differ in their pericentromeric region. This rearrangement has been explained by a simple chromosome translocation between ancestral forms of the two chromosomes (Iannuzzi et al. 2001e). More complex are the rearrangements (transpositions) that modify the size, shape, chromosome banding and gene order of the X-chromosomes in these bovids (Piumi et al. 1998; Iannuzzi et al. 2000).

\section{Acknowledgements}

The authors wish to thank Maud Bertaud and Catherine Denis for the preparation of bovine BAC DNA.

\section{References}

Ansari H.A., Bosma A.A., Broad T.E., Bunch T.D., Long S.E., Maher D.W., Pearce P.D. \& Popescu C.P. (1999) Standard G-, Q- and R-banded ideograms of the domestic sheep (Ovis aries): homology with cattle (Bos taurus). Report of the committee for the standardization of the sheep karyotype. Cytogenetics and Cell Genetics 85, 317-24.

Di Meo G.P., Molteni L., Perucatti A., De Giovanni A., Incarnato D., Succi G., Schibler L., Cribiu E.P. \& Iannuzzi L. (2000) Chromosomal characterization of three centric fusion translocations in cattle using G-, R- and C-banding and FISH technique. Caryologia 53, 213-8.

Gautier M., Laurent P., Hayes H. \& Eggen A. (2001) Development and assignment of bovine specific PCR systems for the Texas nomenclature marker genes and isolation of homologous BAC clones. Genetique Seletion Evolution 33, 191-200.

Hayes H., Di Meo G.P., Gautier M., Laurent P., Eggen A. \& Iannuzzi L. (2000) Localization by FISH of the 31 Texas nomenclature type I markers to both Q- and R-banded bovine chromosomes. Cytogenetics and Cell Genetics, 90, 315-20.

ISCNDB2000 (2001) International System for Chromosome Nomenclature of Domestic Bovids, Di Berardino D., Di Meo G.P., Gallagher D.S., Hayes H. \& Iannuzzi L. (coordinator), eds. Cytogenetics and Cell Genetics, 92, 283-99.

Iannuzzi L., Ferretti L., Di Meo G.P. \& Perucatti A. (1997) FISHmapping of bovine U21, U1 and U7 molecular markers to river buffalo chromosomes 3p, 5q and 5p. Chromosome Research, 5, 337-40.

Iannuzzi L., Di Meo G.P., Perucatti A., Incarnato D., Schibler L. \& Cribiu E.P. (2000) Comparative FISH-mapping of bovid X chromosomes reveals homologies and divergences between the subfamilies Bovinae and Caprinae. Cytogenetics and Cell Genetics 89, $171-6$.

Iannuzzi L., Di Meo G.P., Hayes H., Perucatti A., Incarnato D., Gautier M. \& Eggen A. (2001a) FISH-mapping of the 31 bovine Texas markers to river buffalo chromosomes. Chromosome Research 9, 339-42.

Iannuzzi L., Di Meo G.P., Leifsson P.S., Eggen A. \& Christensen K. (2001b) A case of trisomy 28 in cattle revealed by both banding and FISH-mapping techniques. Hereditas 134, 147-51.

Iannuzzi L, Di Meo G.P., Perucatti A., Eggen A., Incarnato D., Sarubbi F. \& Cribiu E. (2001c) A pericentric inversion in cattle Y-chromosome. Cytogenetics and Cell Genetics 94, 202-5.

Iannuzzi L., Molteni L., Di Meo G.P., De Giovanni A., Perucatti A., Succi G., Incarnato D., Eggen A. \& Cribiu E.P. (2001d). A case of azoospermia in a cattle bull carrying an Y-autosome reciprocal translocation. Cytogenetics and Cell Genetics 95, 225-7.

Iannuzzi L., Di Meo G.P., Perucatti A., Schibler L., Incarnato D., Cribiu E.P. (2001e) Comparative FISH-mapping in river buffalo and sheep chromosomes: assignment of forty autosomal type I loci from sixteen human chromosomes. Cytogenetics and Cell Genetics 94, 43-8.

Piumi F., Schibler L., Vaiman D., Outstrip A. \& Cribiu E.P. (1998) Comparative cytogenetic mapping reveals chromosome rearrangements between the $\mathrm{X}$ chromosomes of two closely related mammalian species (cattle and goats). Cytogenetics and Cell Genetics, 81, 36-41.

Texas Conference (1996) Standardization of cattle karyotype nomenclature: report of the committee for the standardization of the cattle karyotype (Popescu C.P., Long S., Riggs P., Womack J., Schmutz S., Fries R. \& Gallagher D., eds), Cytogenetics and Cell Genetics 74, 259-61. 